\title{
Atmosphere-ice forcing in the transpolar drift stream: results from the DAMOCLES ice-buoy campaigns 2007-2009
}

\author{
M. Haller ${ }^{1}$, B. Brümmer ${ }^{2}$, and G. Müller ${ }^{2}$ \\ ${ }^{1}$ Institute of Coastal Research, Helmholtz-Zentrum Geesthacht, Germany \\ ${ }^{2}$ Meteorological Institute, University of Hamburg, Hamburg, Germany \\ Correspondence to: B. Brümmer (burghard.bruemmer@zmaw.de)
}

Received: 18 May 2013 - Published in The Cryosphere Discuss.: 24 July 2013

Revised: 18 December 2013 - Accepted: 8 January 2014 - Published: 20 February 2014

\begin{abstract}
During the EU research project Developing Arctic Modelling and Observing Capabilities for Long-term Environmental Studies (DAMOCLES), 18 ice buoys were deployed in the region of the Arctic transpolar drift (TPD). Sixteen of them formed a quadratic grid with $400 \mathrm{~km}$ side length. The measurements lasted from 2007 to 2009. The properties of the TPD and the impact of synoptic weather systems on the ice drift are analysed. Within the TPD, the speed increases by a factor of almost three from the North Pole to the Fram Strait region. The hourly buoy position fixes would show that the speed is underestimated by $10-20 \%$ if positions were taken at only 1-3 day intervals as it is usually done for satellite drift estimates. The geostrophic wind factor $U_{\mathrm{i}} / U_{\mathrm{g}}$ (i.e. the ratio of ice speed $U_{\mathrm{i}}$ and geostrophic wind speed $U_{\mathrm{g}}$ ), in the TPD amounts to 0.012 on average, but with regional and seasonal differences. The constant $U_{\mathrm{i}} / U_{\mathrm{g}}$ relation breaks down for $U_{\mathrm{g}}<5 \mathrm{~m} \mathrm{~s}^{-1}$. The impact of synoptic weather systems is studied applying a composite method. Cyclones (anticyclones) cause cyclonic (anticyclonic) vorticity and divergence (convergence) of the ice drift. The amplitudes are twice as large for cyclones as for anticyclones. The divergence caused by cyclones corresponds to a $0.1-0.5 \%$ per $6 \mathrm{~h}$ open water area increase based on the composite averages, but reached almost $4 \%$ within one day during a strong August 2007 storm. This storm also caused a long-lasting (over several weeks) rise of $U_{\mathrm{i}}$ and $U_{\mathrm{i}} / U_{\mathrm{g}}$ and changed the ice conditions in a way which allowed large amplitudes of inertial ice motion. The consequences of an increasing Arctic storm activity for the ice cover are discussed.
\end{abstract}

\section{Introduction}

The transpolar drift (TPD) is, together with the Beaufort gyre, one of the two large systems of sea-ice drift and nearsurface currents in the Arctic Ocean. The TPD starts along the Siberian coast, progresses to the North Pole region, and ends in the Fram Strait. About $3000 \mathrm{~km}^{3}$ of sea ice per year are transported with the TPD from the Arctic Ocean into the North Atlantic. This will correspond to $15 \%$ of the Arctic Ocean area if we assume an average ice thickness of $2 \mathrm{~m}$. The ice export through Fram Strait shows large seasonal to inter-annual variations with amplitudes being about $50 \%$ of the mean value (e.g. Affeld, 2003; Kwok et al., 2004). The speed of the TPD is also characterized by large variations showing high correlation with the east-west pressure gradient on the timescale of monthly to seasonal means (Vihma et al., 2012). The speed of the TPD in the preceding winter and summer affects the sea-ice extent minimum in the following September. A stronger TPD leads to a shorter stay of the sea ice in the Arctic Ocean and increases the ice export through Fram Strait. Smedsrud et al. (2011) showed that the recent (2004-2010) high sea-ice area export in the Fram Strait contributed to the Arctic sea-ice decline. A positive trend of the TPD speed for the period 1950-2006 was analysed by Hakkinen et al. (2008) using drift observations from the Russian North Pole stations, various expedition camps, and International Arctic Buoy Program (IABP). Also based on IABP data (1979-2007), Rampal et al. (2009) found a positive trend for both the mean speed and the deformation rate of the Arctic sea ice. The positive trend in drift speed is not accompanied by a comparable trend in wind speed but correlates with a decrease of multiyear ice, as was shown by 
Kwok et al. (2013) using IABP buoy and satellite-based drift data (1979-2009). The positive trend in drift speed is also underlined by comparing individual drift trajectories in the TPD. For example, the drift time of the French vessel Tara from the Siberian side to Fram Strait in 2006-2007 was about half as long as the drift time of the Norwegian vessel Fram in 1893-1896 for about the same distance (Gascard et al., 2008).

The September ice extent minimum is mainly the integral result of the Fram Strait ice export and the summertime ice melt which depends on many factors such as the conditions at the end of winter of ice thickness and concentration, the ocean temperature, the solar insolation, which is closely related to cloud cover, and the warm-air advection from the surrounding land areas in summer. The latter are strongly controlled by synoptic pressure systems. For example, Screen et al. (2011) show that with more cyclonic activity over the Arctic Ocean in spring and summer, the sea ice extent minimum in the following September is higher. Among other reasons, the sea ice appears to be better protected from melting due to a higher amount of clouds. On the other hand, cyclones cause a deformation of the ice and a decrease of ice concentration of the order of a few percent (Kriegsmann and Brümmer, 2013). In contrast to winter, the resulting openings remain open in summer and, thus, due to the positive albedo feedback, the ice melt can be increased. Furthermore, the decline of ice concentration reduces the internal forces and increases the mobility of the ice.

In this paper, we focus on the synoptic scale and investigate the impact of synoptic weather systems on the properties of the TPD. This is done by using data from an array of 16 ice buoys which were deployed in April 2007 around the above-mentioned French vessel Tara and data from two further buoys deployed in 2008. The measurements of the buoy array lasted until January 2008 and those of the other two buoys until 2009 and, thus, cover the period of the so far second-lowest ice extent minimum in September 2007 (the lowest occurred in September 2012). The experimental investigations aimed primarily at the following questions: (a) what are the kinematic properties of the TPD in the time range from hourly to seasonal? (b) How variable is the atmospheric dynamical forcing and what are the impacts of synoptic weather systems on the TPD? (c) What is the impact of a strong summer storm on the sea ice on a short timescale and longer?

The paper is organized along these questions. In Sect. 2 the buoys, their deployment, the data collection and the calculation of drift are described. Section 3 deals with the kinematic properties of the TPD for different seasons and locations. In Sect. 4 the atmospheric wind forcing and the forcing-drift relation are investigated. Section 5 presents a composite study of the impact of cyclones and anticyclones on the vorticity, divergence and deformation of the ice drift and Sect. 6 deals with a case study of the strong summer storm on 13 August
2007 and its long-term consequences. A summary and conclusions are given in Sect. 7.

\section{The DAMOCLES ice-buoy campaigns}

In this study, we use data from two ice-buoy campaigns called here DAMOCLES 2007 (D07) and DAMOCLES 2008 (D08). Both field campaigns were operated by the Meteorological Institute of the University of Hamburg within the framework of the integrated research project DAMOCLES (Developing Arctic Modelling and Observing Capabilities for Long-term Environmental Studies) which was funded by the European Commission.

The D07 campaign used 16 CALIBs (Compact AirLaunch Ice Buoys) manufactured by the Canadian company MetOcean (Fig. 1). Buoys and data are described in a data publication (Brümmer et al., 2011a). The buoys were equipped with Alkali batteries for power supply, with a Vaisala PMB-100 pressure sensor and an YSI thermistor temperature sensor. The position was determined by the ARGOS satellite system with an accuracy of about $300 \mathrm{~m}$. The buoy data were transmitted in irregular time intervals depending on the available satellite coverage. In the post-processing procedure the data were despiked and interpolated to regular $1 \mathrm{~h}$ intervals. Hourly drift velocities were calculated over $2 \mathrm{~h}$ intervals and shifted by $1 \mathrm{~h}$. The buoys were deployed in a regular $4 \times 4$ quadratic grid of $400 \mathrm{~km}$ by $400 \mathrm{~km}$ side length centred at the French sailing vessel Tara (see also Figs. 3 and 4) on 22 and 23 April 2007 with a Twin Otter aircraft which could land and refuel on the ice near Tara. The buoys numbers were as follows: 1-4 (first row), 5-8 (second row), 9-12 (third row), and 13-16 (fourth row) (see Fig. 4). Since the buoys were dropped from the aircraft and landed uncontrolled, their exposure on the ice (ridge, trough, thin or thick ice, near a fracture) is unknown. This uncertainty makes it difficult to find out why the buoys were lost earlier or later. The buoy data availability is given in Fig. 2. The first buoy (no. 15) was lost already on 22 May 2007. In the following summer month, a further 13 buoys were temporarily lost, six of them recovered after some time. We are not sure what actually happened, but the Tara scientists reported a high fraction of melt ponds on the ice. This observation is supported by Rösel and Kaleschke (2012) who analysed from satellite data an exceptional melt pond occurrence in the Arctic in 2007. So, we assume that the buoys were partly submerged in the water, but could submit data again after summer when the melt ponds drained and disappeared. Ultimately, seven buoys survived the melting season. Out of these seven buoys, only three buoys passed the Fram Strait in November/December 2007. The last buoy (no. 5) ended on 31 January 2008 near $70^{\circ} \mathrm{N}$ in the East Greenland Current.

Within the D08 campaign nine PAWS (Polar Area Weather Station) ice buoys (also manufactured by the Canadian company MetOcean) were deployed (Fig. 1). PAWS and data are 

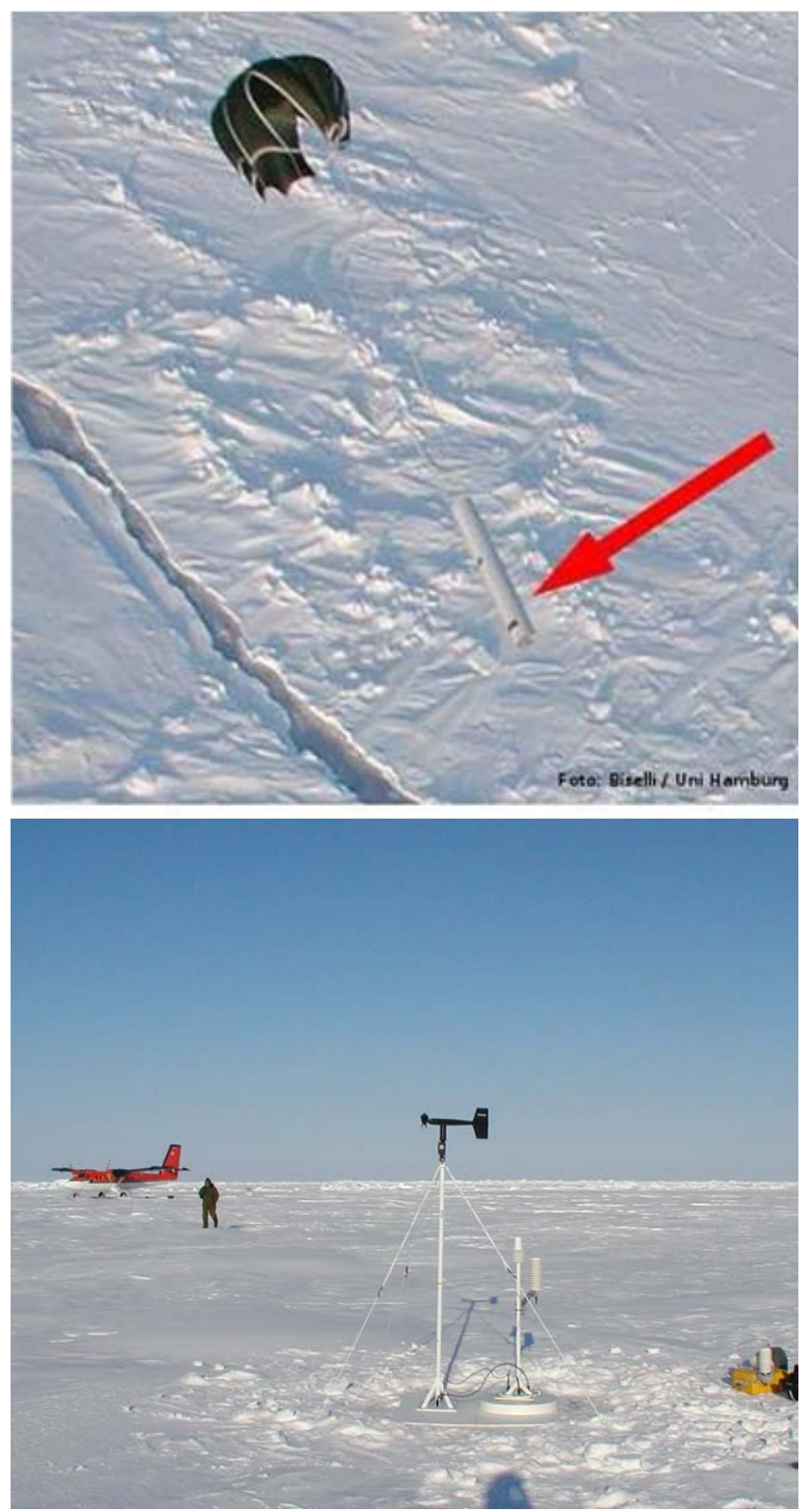

Fig. 1. Above: CALIB buoy dropped from Twin Otter aircraft at $300 \mathrm{~m}$ altitude and descending on parachute. Below: PAWS buoy $\mathrm{G}$ after installation with Twin Otter aircraft landed on ice.

described in a data publication (Brümmer et al., 2011b). The PAWS were equipped with a Lithium battery for power supply, and with sensors for pressure, air temperature, ice temperature, relative humidity, and wind vector (Young). The position was determined via GPS and thus is accurate to about $10 \mathrm{~m}$. The data were transmitted via Iridium at regular 3hourly intervals (00:00, 03:00, etc.; all times in UTC). The drift velocities were calculated over $3 \mathrm{~h}$ intervals. The complex instrumentation of the PAWS required manual installation on the ice. Seven of the PAWS, labelled A to G, were deployed between 12 and 22 April 2008 north of Ellesmere Island with the help of a Twin Otter aircraft (seven flight mis-
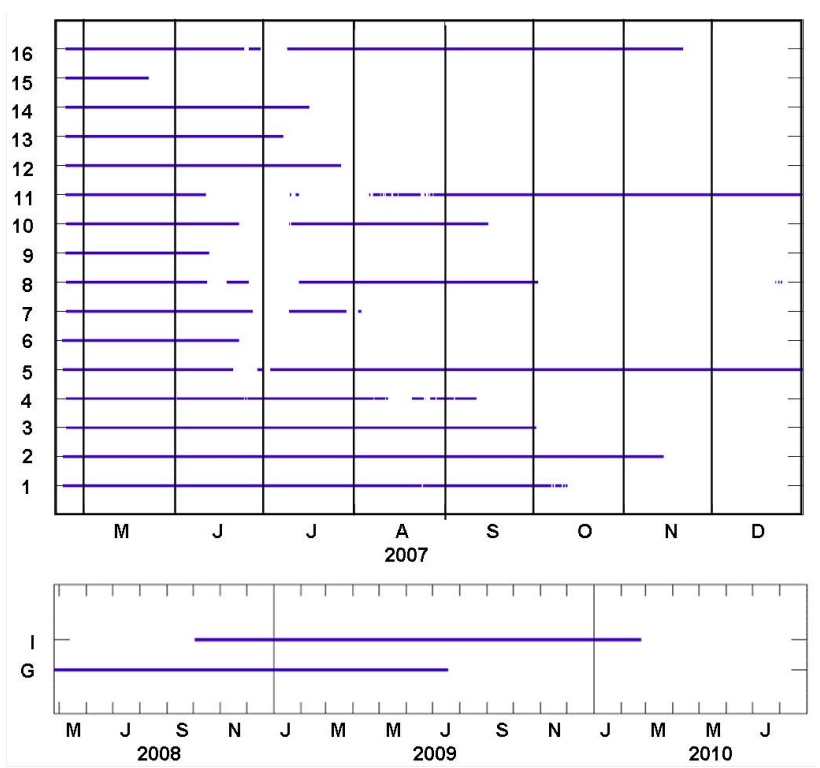

Fig. 2. Data availability for all 16 CALIB buoys in 2007 (top) and of PAWS buoys G, I in 2008-2010 (below).

sions) operating from Eureka airfield. Two further PAWS $(\mathrm{H}$, I) were originally also planned to be deployed in that region, but did not work properly and, thus, had to be repaired by MetOcean. They were deployed later by the German R/V Polarstern, during the first cruise of a ship around the ice cap of the Arctic Ocean, on 21 September 2008 in the Beaufort Sea $(\mathrm{H})$ and on 3 October 2008 in the Laptev Sea (I). In this paper, we use data only from the PAWS buoys G and I which moved with the TPD and reached the Fram Strait. The data availability is given in Fig. 2. The buoys measured data until 18 July 2009 (G) and 23 February 2010 (I), thus covering periods of more than one or even two years, respectively.

The D07 campaign during the summer 2007 ice extent minimum took place around Tara which began its drift in September 2006 at about $79.8^{\circ} \mathrm{N}, 145^{\circ} \mathrm{E}$ not far north of the ice edge.

Figure 3 shows the ice concentration on 1 May, 1 July, and 1 September 2007 together with the positions of the four corner buoys $1,4,13$, and 16 of the D07 buoy square. The ice melt in 2007 which advanced northward beginning from the Beaufort Sea, Chukchi Sea, and East Siberian Sea fortunately did not reach the D07 buoy array, although on the satellite image for 1 July small areas with little ice concentration are discernible in that part of the buoy array where the first buoy (no. 15) was lost. So, from the knowledge of the September 2006 ice edge which was close to Tara's drift start and the knowledge of the September 2007 ice edge, it can be concluded that the ice melt in 2007 mainly concerned the new first year ice, but not all of it since the distance of Tara from the September 2007 ice edge was farther than its distance from the September 2006 ice edge. 


\section{Drift characteristics}

Figure 4 shows the drift of the D07 array and the PAWS G and I. Also shown is the drift of Tara from September 2006 until 23 April 2007. Afterwards, the Tara drift is not plotted because it forms the centre of the D07 array and the Tara drift is well represented by the surrounding buoys (e.g. by the long-lasting buoy 11). Although with a time difference of two years, Tara and PAWS I start in about the same region of the Arctic Ocean at about the same time of the year (October) and drift along a similar track in about the same time. In April 2009, PAWS I is almost in the same region where the D07 array started. PAWS G, further in the west of the TPD, begins its track one year later than the array and one year earlier than PAWS I, but at the same time of the year (April). The drift of PAWS G from May to September is similar to that of the array, but later it moves towards the southwest and gets stuck from October 2008 to January 2009 in the very dense pack ice north of Greenland. Afterwards, PAWS G is again captured by the TPD and moves eastward north of the ice shear zone along the land-fast ice at the coast of North Greenland. Finally, PAWS G passes the Fram Strait $\left(80^{\circ} \mathrm{N}\right)$ in March 2009, while PAWS I and the remaining buoys of the array $(5,11$, and 16$)$ pass $80^{\circ} \mathrm{N}$ about 3-4 months earlier.

Apart from the winter period when PAWS G got stuck in the pack ice north of Greenland, all buoys show an acceleration of the TPD from the region around the North Pole to the Fram Strait and the East Greenland Current. This can be seen in the drift speed histograms for PAWS G, I, and the D07 buoys 5,11 , and 16 displayed in Fig. 5. The median values of drift speed (see Table 1) are around $7.5 \mathrm{~cm} \mathrm{~s}^{-1}$ in the region north of $85^{\circ} \mathrm{N}$ during the months May to September. The values increase in October and November further south, but still north of the Fram Strait, to median values around $13 \mathrm{~cm} \mathrm{~s}^{-1}$ and then accelerate in the Fram Strait and south of it to median values around $21 \mathrm{~cm} \mathrm{~s}^{-1}$. So the speed of the TPD increases by a factor of 2.7 from the North Pole to Fram Strait. The speed acceleration within the TPD is accompanied by a convergence of the ice drift towards Fram Strait as can be seen in Fig. 4. From our Lagrange buoy measurements it is difficult to separate regional and seasonal differences. However, the downstream regional increase by a factor of 2.7 is much larger than the typical seasonal drift speed variation in the Arctic (e.g. Rampal et al., 2009).

The drift trajectories in the TPD region do not follow smooth straight lines, but show curves and loops instead. This results from the variability of the atmospheric forcing due to passing synoptic weather systems. Their influence is further detailed in Sects. 5 and 6. Thus, when the position of an ice floe is taken at large time intervals (e.g. of one or more days), as it is typically done for the estimation of ice drift from satellite data, the length of the trajectory and consequently the drift speed is underestimated. This is underlined in Fig. 6 showing the length of the trajectory calculated with different time steps. The speed underestimate is of the order
Table 1. Median values of drift speed in $\mathrm{cm} \mathrm{s}^{-1}$ for five buoys in different regions of the transpolar drift stream.

\begin{tabular}{lrrr}
\hline Buoy & $>85^{\circ} \mathrm{N}$ & $\begin{array}{r}85^{\circ} \mathrm{N}- \\
\text { Fram Strait } \\
(\text { Oct-Nov) }\end{array}$ & Fram Strait \\
& (Dec-Jan) \\
\hline 5 & 6.5 & 12 & 18 \\
11 & 7.5 & 11 & 22.5 \\
16 & 7 & 16 & - \\
$\mathrm{G}$ & 7 & 4 & 10 \\
$\mathrm{I}$ & 9 & 13 & 21.5 \\
\hline Mean & $7.5 \mathrm{~cm} \mathrm{~s}^{-1}$ & $13.0 \mathrm{~cm} \mathrm{~s}^{-1}$ & $20.7 \mathrm{~cm} \mathrm{~s}^{-1}$ \\
(without G) & & & \\
\hline
\end{tabular}

of $10 \%$ for $24 \mathrm{~h}$ intervals, of $20 \%$ for 3 day intervals, and of $30-50 \%$ for monthly time steps.

The area and the orientation of the D07 array show no monotonous variation with time. The array area increases slightly due to stretching of the lines $1-4$ and $4-16$, while 1-13 and 13-16 remain almost constant. The rotation is predominantly anticyclonic in May and June and changes to predominantly cyclonic from August until November. Furthermore, the variation of divergence and rotation is nonuniform for the various sub-areas. This is due to the fact that the entire array is rarely under the same atmospheric forcing. Passing lows and highs affect the different sub-areas in a different manner. In addition, inhomogeneous ice conditions (ice thickness, concentration, strength) can result in small horizontal correlations of the ice kinematic properties such as divergence or deformation. From the analysis of buoy data, Hutchings et al. (2012) found no coherent length scale for the horizontal variation of ice-drift divergence because the internal ice stress varied on short-length scales of the order of $10 \mathrm{~km}$. Also, Rampal et al. (2008) conclude that the Arctic sea-ice deformation is heterogeneous and intermittent based on the analysis of IABP data.

\section{Wind-drift relation}

The wind is the primary forcing for ice drift over timescales ranging from synoptic (e.g. Lammert et al., 2009; Brümmer et al., 2008) to climate (e.g. Vinje, 2001; Vihma et al., 2012). The relation between drift and wind is often represented in the literature by the wind factor, WF (ratio drift vs. wind), and the deviation angle, DA (positive for ice drift to the right of the wind). WF and DA are relatively easily accessible from observations and are indirect indicators for the importance of the individual forces in the ice momentum balance equation. In case of a free-ice drift (internal ice force negligible which is typically assumed for ice concentrations below 0.8 , Leppäranta, 2005, p. 141) and thin ice (Coriolis force negligible), WF is the square root of the ratio of the products of density 


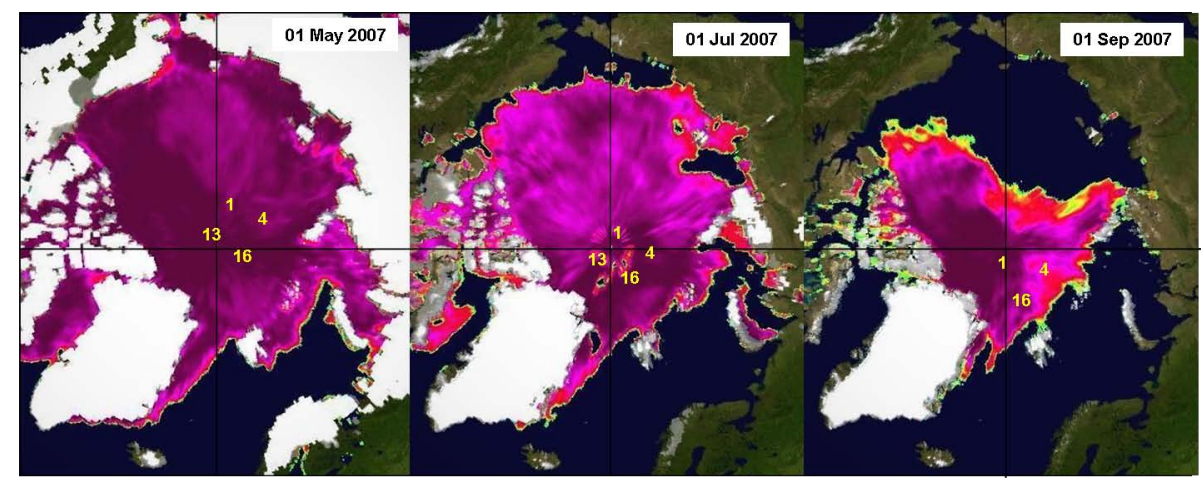

Fig. 3. Ice extent and concentration on 1 May, 1 July, and 1 September 2007 (from The Cryosphere Today; http://arctic.atmos.uiuc.edu/ cryosphere/) together with location of the four corner buoys 1, 4, 13, and 16 of the D07 buoy array.

and drag coefficient in atmosphere and ocean. With increasing ice thickness (i.e. increasing Coriolis force), the WF decreases and the DA increases (Leppäranta, 2005, p. 144). In case of ice concentrations above 0.8 , the internal ice force has to be taken into account. It is about opposite to the drift and acts towards a decrease of WF and DA (Thorndike and Colony, 1982).

Since the wind was not measured at the D07 buoys, we use the geostrophic wind instead. We calculate the geostrophic wind, $U_{\mathrm{g}}$, from the sea-level pressure field of the 6-hourly operational ECMWF (European Centre for Medium-Range Weather Forecast) analysis which has a horizontal resolution of $0.25^{\circ}$. First, $U_{\mathrm{g}}$ is determined at each grid point of the model analysis, and then interpolated to the buoy position. Calculating $U_{\mathrm{g}}$ from the D07 buoy pressure field would have been an option, but appeared to be too uncertain especially because 12 of the 16 buoys are at the edge of the buoy array. The ECMWF pressure field has a high degree of validity. The temporal pressure correlation between ECMWF and D07 buoys is higher than 0.99 for each buoy (Haller, 2011).

Figure 7 shows time series of ice drift $U_{\mathrm{i}}$, geostrophic wind $U_{\mathrm{g}}$, and geostrophic wind factor (ratio of $U_{\mathrm{i}}$ vs. $U_{\mathrm{g}}$ ) for all buoys of the D07 array. $U_{\mathrm{i}}$ and $U_{\mathrm{g}}$ show a similar variation. Maxima of $U_{\mathrm{g}}$ always correspond to maxima of $U_{\mathrm{i}}$. However, this is not true for the minima. The ratio $U_{\mathrm{i}} / U_{\mathrm{g}}$ is $1.2 \%$ on average; spikes occur when $U_{\mathrm{g}}$ is low. The amplitudes of the $U_{\mathrm{i}}$ and $U_{\mathrm{i}} / U_{\mathrm{g}}$ variations show a distinct step to higher values in August, although the amplitude of the $U_{\mathrm{g}}$ variations is almost the same from April to October 2007. This step is caused by a strong summer storm on 13 August 2007 as will be outlined in Sect. 6 .

The variation of ice drift $U_{\mathrm{i}}$ and deviation angle, $\alpha_{\mathrm{i}}-\alpha_{\mathrm{g}}$, as function of $U_{\mathrm{g}}$ is presented in Fig. 8. Values of $U_{\mathrm{g}}$ reach up to $30 \mathrm{~m} \mathrm{~s}^{-1}$, the median is $7 \mathrm{~m} \mathrm{~s}^{-1}$. For values $U_{\mathrm{g}}>5 \mathrm{~m} \mathrm{~s}^{-1}$, an almost constant ratio of $U_{\mathrm{i}} / U_{\mathrm{g}}=0.0115$ is present. For values $U_{\mathrm{g}}<5 \mathrm{~m} \mathrm{~s}^{-1}$, the ratio increases due to the inertia of the ice motion and the ocean current. The angle difference $\alpha_{\mathrm{i}}-\alpha_{\mathrm{g}}$ is around $10^{\circ}$ and shows no clear trend with $U_{\mathrm{g}}$. The results, concerning $U_{\mathrm{i}} / U_{\mathrm{g}}$, fit well into the range of earlier studies (e.g. Thorndike and Colony, 1982), but disagree concerning $\alpha_{\mathrm{i}}-\alpha_{\mathrm{g}}$. Earlier studies indicate a higher deviation angle with decreasing $U_{\mathrm{g}}$.

The ratio $U_{\mathrm{i}} / U_{\mathrm{g}}$ and the deviation angle $\alpha_{\mathrm{i}}-\alpha_{\mathrm{g}}$ show a clear variation when distinguishing with respect to region and season as presented in Table 2. For this, we have used monthly means from all data of the D07 array and the PAWS G and I. The regions Siberia (defined here as $<85^{\circ} \mathrm{N}$, $>90^{\circ} \mathrm{E}$ ) and North Pole (defined here as $>85^{\circ} \mathrm{N}$ ) have a similar range of $U_{\mathrm{i}} / U_{\mathrm{g}}$ values with minima $<1.0 \%$ in late winter and maxima $>1.5 \%$ in summer. The $U_{\mathrm{i}} / U_{\mathrm{g}}$ values for buoy $\mathrm{G}$ in the dense pack ice north of Greenland are always $<1 \%$ in autumn and winter. In contrast, the $U_{\mathrm{i}} / U_{\mathrm{g}}$ values in the Fram Strait are the largest ones around $2 \%$ even in winter. The deviation angle $\alpha_{\mathrm{i}}-\alpha_{\mathrm{g}}$ shows a distinct annual cycle in the regions Siberia/North Pole from small values $\left(-3^{\circ}\right.$ to $\left.2^{\circ}\right)$ in winter to larger values $\left(17^{\circ}\right.$ to $\left.18^{\circ}\right)$ in summer. In winter, the angle difference is small $\left(3^{\circ}\right.$ to $\left.6^{\circ}\right)$ north of Greenland and in the typical range $\left(5^{\circ}\right.$ to $\left.10^{\circ}\right)$ in the Fram Strait region.

The ratio $U_{\mathrm{i}} / U_{\mathrm{g}}$ and the deviation angle $\alpha_{\mathrm{i}}-\alpha_{\mathrm{g}}$ depend on the local ice conditions (thickness, concentration) and, thus, on the relative magnitude of Coriolis force and internal ice stress. Ice conditions were even different within the comparatively small D07 array as can be inferred from Table 3. In May/June, buoys 1-8 (see Fig. 4) have clearly larger $U_{\mathrm{i}} / U_{\mathrm{g}}$ values (indicating thinner and less compact ice) than the other buoys. These spatial differences within the buoy array still exist in August/September, although the average $U_{\mathrm{i}} / U_{\mathrm{g}}$ level has increased from $1.09 \%$ to $1.39 \%$ between these two time periods. The continued existence of spatial differences underlines the potential long-term (here 5 months) memory in the ice cover characteristics.

\section{Impact of synoptic systems: cyclones and anticyclones}

In this section we analyse the impact of cyclones and anticyclones on vorticity, divergence and deformation (magnitude of the shear strain rates) of the sea ice which are defined as 
Table 2. Monthly averages of $U_{\mathrm{i}} / U_{\mathrm{g}}$ in $\%$ and difference angle $\alpha_{\mathrm{i}}-\alpha_{\mathrm{g}}$ in four regions of the transpolar ice drift based on data from the D07 array and the PAWS buoys $\mathrm{G}$ and $\mathrm{I}$.

\begin{tabular}{|c|c|c|c|c|c|c|c|c|c|c|c|c|c|}
\hline Month & $\mathrm{J}$ & F & M & A & M & $\mathrm{J}$ & J & A & $\mathrm{S}$ & $\mathrm{O}$ & $\mathrm{N}$ & D & Source \\
\hline Siberia & $\begin{array}{c}1.15 \\
1^{\circ}\end{array}$ & $\begin{array}{l}0.95 \\
-2^{\circ}\end{array}$ & $\begin{array}{l}0.80 \\
-3^{\circ}\end{array}$ & $\begin{array}{c}1.12 \\
4^{\circ}\end{array}$ & & & & & $10^{\circ}$ & $\begin{array}{c}1.45 \\
5^{\circ}\end{array}$ & $\begin{array}{c}1.20 \\
2^{\circ}\end{array}$ & 1.10 & I \\
\hline North Pole & & & & & $\begin{array}{l}1.04 \\
14^{\circ}\end{array}$ & $\begin{array}{l}1.08 \\
17^{\circ}\end{array}$ & $\begin{array}{l}1.58 \\
17^{\circ}\end{array}$ & $\begin{array}{l}1.45 \\
18^{\circ}\end{array}$ & $\begin{array}{c}1.30 \\
?\end{array}$ & & & & $\begin{array}{l}\text { Array, } \\
\text { G, I }\end{array}$ \\
\hline Greenland & & & & & & & & & & $\begin{array}{c}0.85 \\
3^{\circ}\end{array}$ & $\begin{array}{c}0.89 \\
6^{\circ}\end{array}$ & $\begin{array}{c}0.94 \\
4^{\circ}\end{array}$ & $\mathrm{G}$ \\
\hline Fram Strait & & & $\begin{array}{l}1.80 \\
10^{\circ}\end{array}$ & & & & & & & & & $\begin{array}{c}2.20 \\
5^{\circ}\end{array}$ & G, I \\
\hline
\end{tabular}

Table 3. Average ratios of $U_{\mathrm{i}} / U_{\mathrm{g}}$ in $\%$ during the periods May/June and August/September 2007 for all 16 D07 ice buoys. The distance between the D07 array locations for both periods is relatively small. The centre of the array is at $88.2^{\circ} \mathrm{N}, 080^{\circ} \mathrm{E}\left(86.3^{\circ} \mathrm{N}, 020^{\circ} \mathrm{E}\right)$ in the middle of the first (second) period.

\begin{tabular}{lrrrrrrrrrrrrrrrr}
\hline Buoy no. & 1 & 2 & 3 & 4 & 5 & 6 & 7 & 8 & 9 & 10 & 11 & 12 & 13 & 14 & 15 & 16 \\
\hline May/Jun & 1.43 & 1.27 & 1.18 & 1.17 & 1.25 & 1.14 & 1.06 & 1.12 & 0.91 & 1.18 & 0.95 & 0.96 & 0.91 & 0.98 & 0.82 & 1.08 \\
Aug/Sep & 1.47 & 1.36 & 1.82 & - & 1.12 & - & - & 1.44 & - & 1.55 & 1.21 & - & - & - & - & 1.11 \\
\hline
\end{tabular}

follows:

$$
\begin{aligned}
& \text { vorticity }=v_{x}-u_{y} \text {, divergence }=u_{x}+v_{y}, \\
& \quad \text { and deformation }=\left[\left(u_{x}-v_{y}\right)^{2}+\left(u_{y}+v_{x}\right)^{2}\right]^{1 / 2} .
\end{aligned}
$$

Only data from the D07 array are used for this analysis. The latitude-longitude buoy positions have been converted, using a polar-stereographic projection, to positions $(x, y)$ and to drift vectors $(u, v)$ in a Cartesian coordinate system centred on the North Pole with the $x$ axis pointing towards $90^{\circ} \mathrm{E}$. The spatial gradients in ice motion, $u_{x}, u_{y}, v_{x}, v_{y}$, are calculated from the tilt of the $u$ - or $v$-plain fitted to the drift vector measurements at three buoys. Vorticity, divergence, and deformation represent kinematic changes of the ice deck. They depend on the atmospheric forcing and on the existing properties of the ice field (e.g. concentration, thickness, ice strength).

As an example, Fig. 9 shows the time series of vorticity and divergence in the buoy triangle 3-10-16 together with the sea-level pressure measured at buoy 11 in the centre. An abrupt change of the amplitude of the vorticity and divergence variations occurs with the passage of the $13 \mathrm{Au}$ gust storm. It can be seen that maxima and minima in the vorticity and divergence curves are mostly related with sealevel pressure extremes. Beside the impact of the particular characteristics of an individual synoptic system on the amplitude of the vorticity, divergence, and deformation variations, the amplitude depends also on the scale of the chosen triangle. The amplitude generally decreases with increasing scale (not shown). This has been analysed in detail by Rampal et al. (2008) and Hutchings et al. (2011).
To study the temporal variation of vorticity, divergence, and deformation of the ice field during the passage of synoptic systems in more detail, but not for each individual system separately, we apply a composite method. Based on the 6-hourly ECMWF sea-level pressure analyses for the fivemonth period from May to September we select 42 cases when a cyclonic system (low, trough or low-pressure line) and 32 cases when an anticyclonic system (high, ridge or bridge) passed over or near the D07 buoy array. During this period the centre of the array was always north of $85^{\circ} \mathrm{N}$ (see Figs. 3 and 4). For each system, we determine a time window of $18 \mathrm{~h}$ centred at the system passage $(t=0 \mathrm{~h})$ which we define as the time when the vorticity attains its maximum (cyclonic system) or minimum (anticyclonic system). Composite averaging is then performed in this relative time frame for 10 different triangles. Due to frequent buoy losses in summer (see Fig. 2), the full number of selected cyclone or anticyclone cases could not be applied for any of the triangles.

The results of the composites are shown in Fig. 10. The amplitudes of the vorticity and divergence variations are roughly about twice as large for cyclonic as for anticyclonic systems. This also holds roughly for the magnitude of deformation. For cyclones, the vorticity is continuously positive within the time window. The largest maximum is found for the small triangle 2-3-8 and the smallest one for the large triangle 1-4-16. Converting vorticity to rotation rates, the composite cyclonic rotation of the ice field is $1.41^{\circ}$ per $18 \mathrm{~h}$ for triangle $2-3-8$ and $0.67^{\circ}$ per $18 \mathrm{~h}$ for triangle $1-4-16$. The peak composite rotation for triangle 2-3-8 at $t=0 \mathrm{~h}$ is $0.14^{\circ} \mathrm{h}^{-1}$ (or $2.52^{\circ}$ per $18 \mathrm{~h}$ ). The divergence composite for 


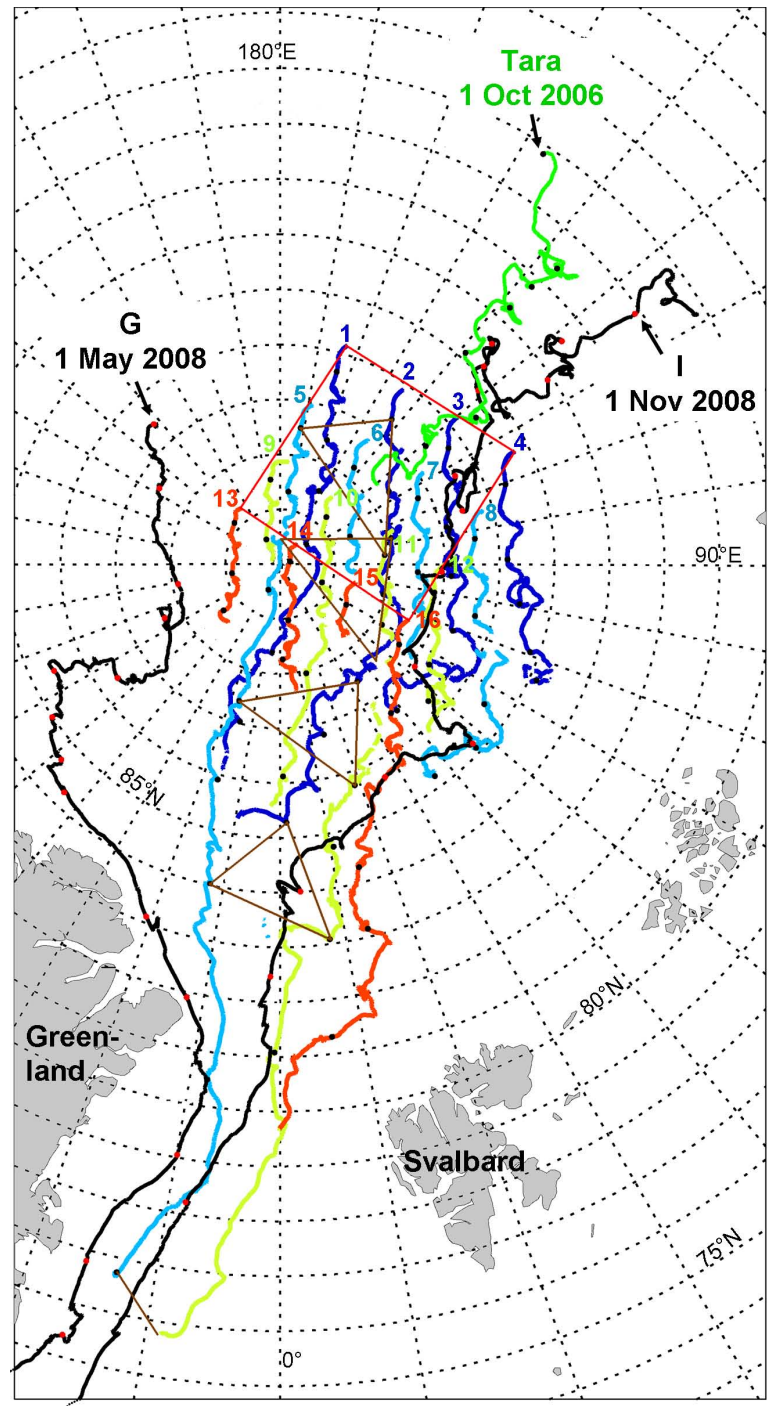

Fig. 4. Drift trajectories of all 16 D07 CALIB buoys, the French sailing vessel Tara (green), and the D08 PAWS buoys G and I (black). Dots in trajectories mark buoy position on first day of each month. Red square surrounds the D07 buoy array at the beginning on 24 April 2007. For a better visualisation of the ice motion the position of the buoy triangle 2-5-11 is given in 2 months intervals on 1 May, 1 July, 1 September, and 1 November 2007.

cyclones shows predominantly a divergent ice drift within the time window. It changes from weakly convergent before to clearly divergent after the passage. The average composite divergence during the first $6 \mathrm{~h}$ after the passage amounts to between 0.05 and $0.25 \times 10^{-6} \mathrm{~s}^{-1}$ corresponding to a relative area increase (i.e. area with new open water between 0.11 and $0.54 \%$ per $6 \mathrm{~h}$ ). The cyclone impact on sea ice has been investigated in numerous model studies using, among others, different approaches for the atmospheric forcing. For example, Haapala et al. (2005) prescribe a moving artificial cyclone, Kawaguchi and Mitsudera (2008) prescribe a stationary artificial cyclone, and Kriegsmann and Brümmer (2013)
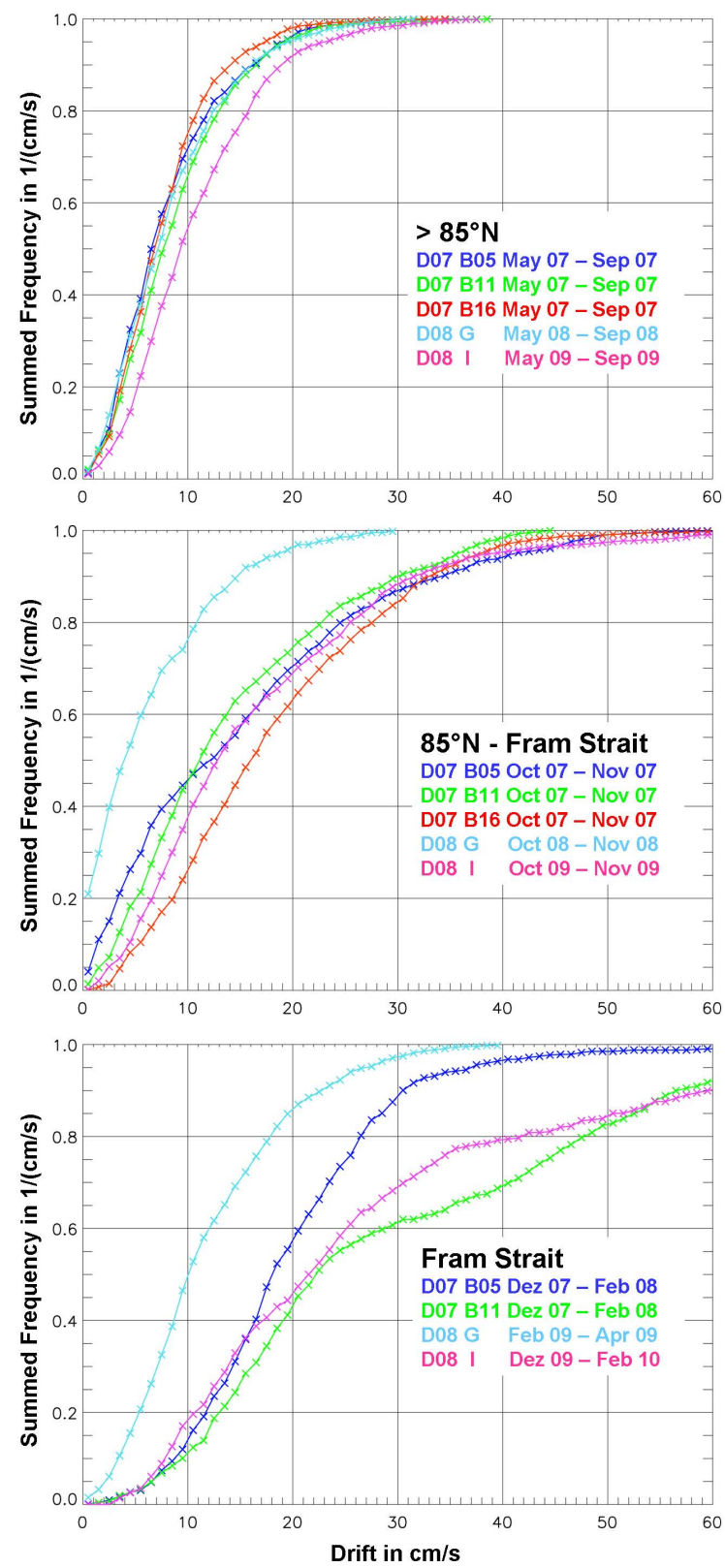

Fig. 5. Histograms of drift velocity for D07 buoys 5, 11, 16 and D08 buoys $\mathrm{G}$, I for different regions of the transpolar drift. Note that the curves hold for different years.

use the pressure field of the operational ECMWF (European Centre of Medium-Range Weather forecast) analysis. Common to all model approaches is that they come up with a decrease of ice concentration of a similar order of magnitude as found here, that is, in a range of -0.5 to $-2 \%$ per $24 \mathrm{~h}$. 

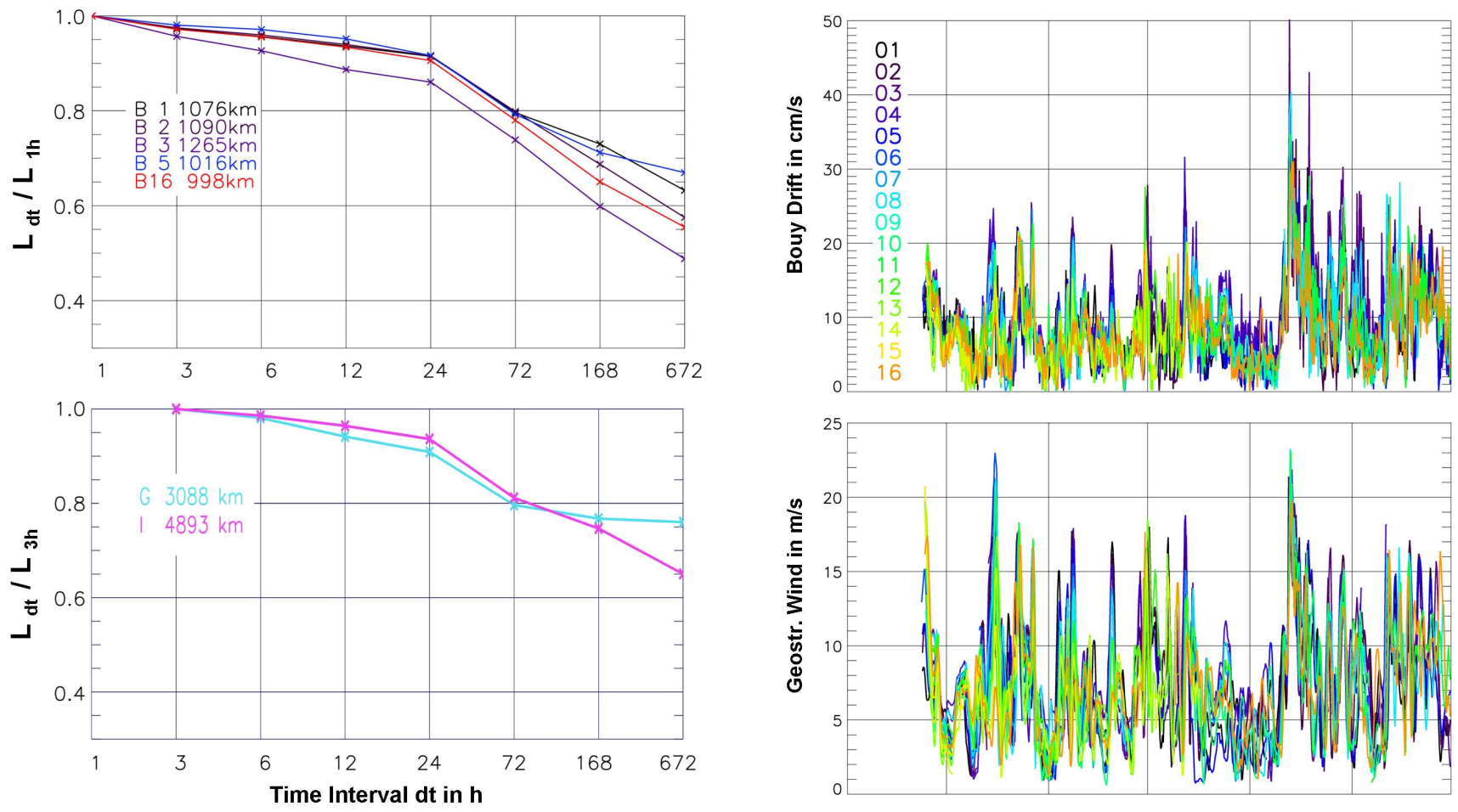

Fig. 6. Normalized length of ice-drift trajectories calculated with different time intervals. The length is normalized by the length (given in the figure) calculated with the shortest time interval which is 1 hour for the CALIB buoys 1, 2, 3, 5, and 16 (above) and $3 \mathrm{~h}$ for the PAWS buoys $\mathrm{G}$ and I (below).

The magnitude of the deformation shows less clear variation during the cyclone passage. However, a weak tendency is indicated: 7 of 10 triangles show a relative or an absolute deformation maximum within $\pm 1 \mathrm{~h}$ around the cyclone passage. This fits to the results from coupled ocean-ice model simulations of Kriegsmann and Brümmer (2013) who find the maximum of deformation in the centre of the cyclone. Deformation is an additional process (in addition to divergence) to change ice concentration. Its effect is usually parameterized in numerical sea-ice models.

Why is the variation of divergence not symmetric with respect to cyclone passage $(t=0)$ ? This is not obvious a priori. We propose the following possible explanation. We assume a rotationally symmetric cyclone which has a band of stronger wind around and weak wind in the centre. When the cyclone approaches, the wind stress works on a not yet modified ice field and the ice starts to drift with an angle of about $10^{\circ}$ to the right of the isobars, thus, leading to convergence. When the cyclone leaves the wind stress is basically the same, but now it works on an already modified ice field where the angle may be larger than $10^{\circ}$ and where, in addition, the onset of an inertial oscillation caused by the just passed strong wind band may cause a further right-hand turning of the ice drift and thus leading to an ice-drift divergence.

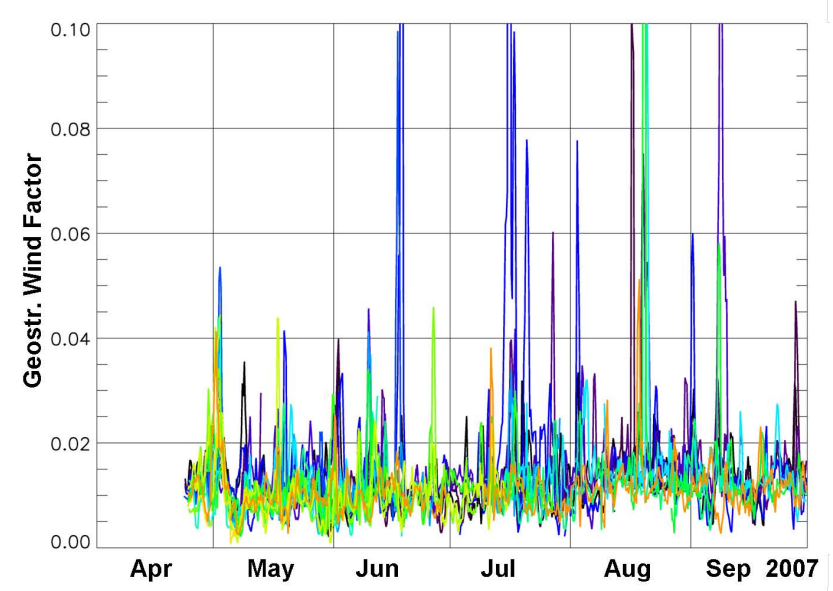

Fig. 7. Time series of 6-hourly ice drift (top), geostrophic wind (middle), and geostrophic wind factor (bottom) for all buoys of the D07 array.

Passing anticyclonic weather systems cause a negative icedrift vorticity throughout the $18 \mathrm{~h}$ time window. The mean composite vorticity is $-0.15 \times 10^{-6} \mathrm{~s}^{-1}$ corresponding to a rotation rate of $-0.56^{\circ}$ per $18 \mathrm{~h}$ averaged over all triangles. The time sequence of ice-drift divergence during anticyclone passages is also asymmetric with respect to $t=0$ and is opposite to that during cyclone passages. Divergence is around zero before the passage and changes to a distinct convergence afterwards. The largest convergence occurs $2-3 \mathrm{~h}$ after the passage. The overall impact of anticyclones is a convergent ice drift of the order of $-0.1 \times 10^{-6} \mathrm{~s}^{-1}$. The deformation shows no uniform variation for all triangles during the 

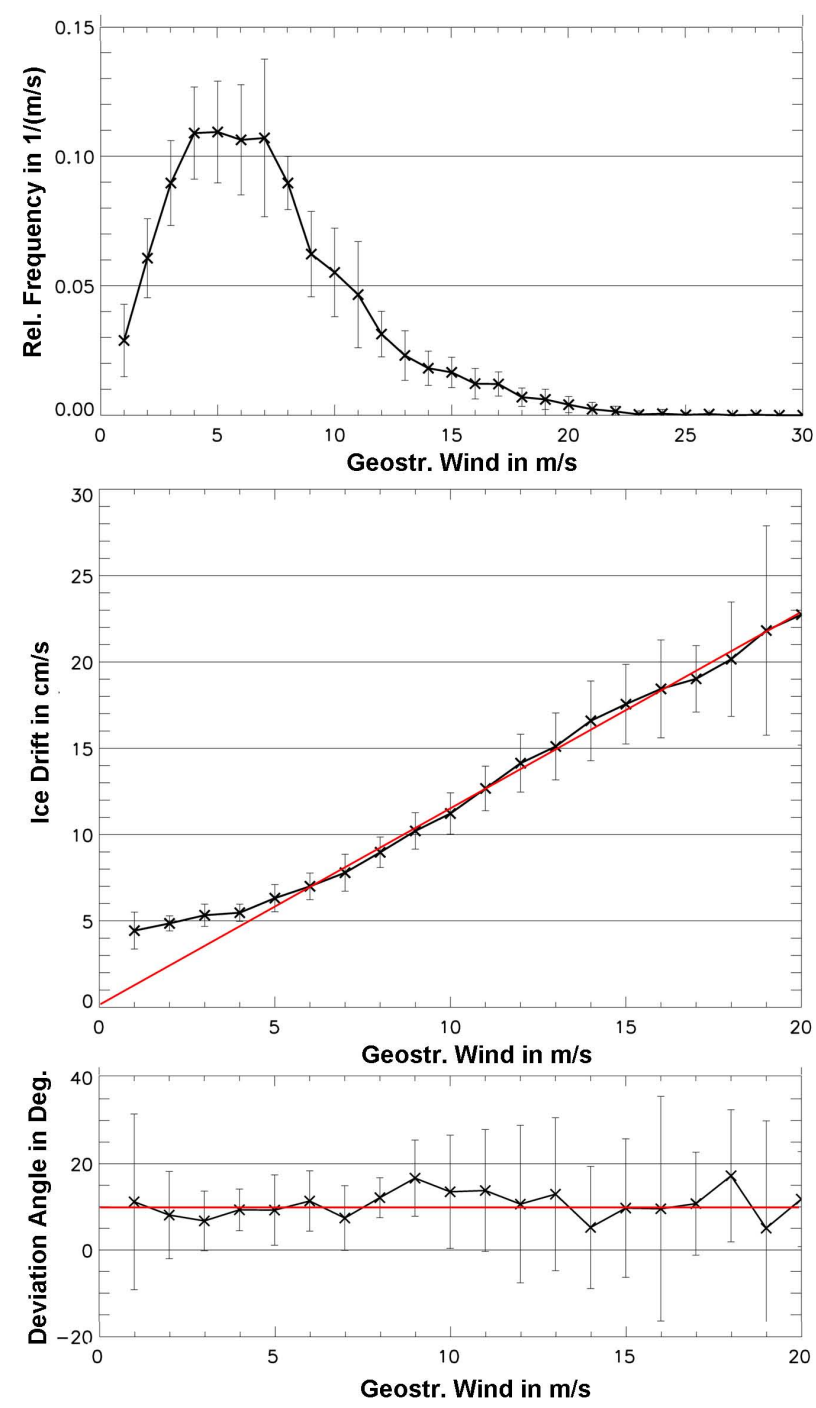

Fig. 8. Frequency distribution of geostrophic wind (top) and variation of magnitude of ice-drift velocity (middle) and deviation angle between ice velocity and geostrophic wind (bottom) for various magnitudes of the geostrophic wind based on all 16 Damocles 2007 buoys for the period 1 May to 30 September 2007.

passage of the anticyclonic system. For 7 of 10 triangles a relative deformation minimum is found within $1-4 \mathrm{~h}$ before the passage. Thus, in contrast to cyclones, the deformation appears to weaken ahead of the anticyclone. This might be related to the fact that, because of dynamical constraints, the horizontal pressure distribution across the centre of an anticyclone cannot be as steep as across the centre of a cyclone. To which degree this cyclone-anticyclone difference is reflected in the deformation composites for the different triangles, depending on the scale of the triangle. A smaller triangle (e.g. 2-3-8) is better suited to reproduce this than a larger triangle (e.g. 1-4-16).

\section{The storm of 13 August 2007}

The composites in Sect. 5 have been calculated for all cyclones regardless of their amplitude. Single storms, however, can have by far larger amplitudes. The manifold consequences which a single strong storm can have, is demonstrated below with the summer storm passing the D07 array on 13 August 2007. To illustrate the synoptic situation, Fig. 11 shows the sea-level pressure fields every $12 \mathrm{~h}$ between 12:00 UTC on 12 August and 00:00 UTC on $14 \mathrm{Au}-$ gust 2007. A cyclone (L1) near Severnaya Zemlya extends a trough northward with a strong storm field on the north and east side of the trough (12 August, 12:00 UTC). Within the trough, a new cyclone (L2) develops moving westward (13 August, 00:00 UTC). The storm field reaches the D07 array with the strongest pressure gradient in the southeast of the array. Cyclone L2 deepens further and takes over the dominating role while simultaneously $\mathrm{L} 1$ weakens to a trough (13 August, 12:00 UTC). The storm field north of ex-L1 is still above the D07 array. Later on 13 August, the wind slows down in the southeast part of D07, but remains strong in the north part (14 August, 00:00 UTC).

Figure 12 shows the time series of drift speed $U_{\mathrm{i}}$ of all buoys in August. A distinct step-like increase of $U_{\mathrm{i}}$ occurs with the storm and $U_{\mathrm{i}}$ values remain high throughout August and even September. Not all buoys of the array were affected in the same way. Particularly buoys 2,3 , and 8 in the "east" part of the array (see Fig. 4) show periodic oscillations which continue for several weeks. The mean period of the oscillations between 13 and 20 August is close to $12 \mathrm{~h}$. Both, the buoy trajectories and the ice velocity hodographs show a right-hand turning of the ice drift superposed to the mean drift. It cannot be distinguished a priori whether the oscillation is of inertial or tidal origin since both have almost identical periods. In Fig. 13, the power spectra of the ice-drift vector are presented for two 12-day periods, one before the storm (1-12 August) and the other after the storm (13-24 August). Before the storm, the spectral power decreases with increasing frequency with embedded small symmetric maxima at \pm 1.9 cycles day $^{-1}$ which represent the semi-diurnal tide (Gimbert et al., 2012). After the storm, the entire spectral power level is higher and a distinct maximum occurs at -1.9 cycles day $^{-1}$ with an amplitude which is at buoy 3 comparable to the mean drift. The maximum represents inertial motions which are particularly pronounced at the buoys 2,3 , and 8 in the southeast of the D07 array where the ice concentration is smallest. Thus, the storm modified the ice conditions within a sub-area of the array (the same sub-area in which already in May/June large $U_{\mathrm{i}} / U_{\mathrm{g}}$ ratios were found, see Table 3 ) in a way allowing large amplitudes of the inertial ice motion. Table 4 shows the spatial distribution of the maximum-minimum differences of the drift oscillations averaged over the period 13-20 August. The highest maximum-minimum difference with $16.2 \mathrm{~cm} \mathrm{~s}^{-1}$ was measured at buoys 2 and 3 . Inertial 


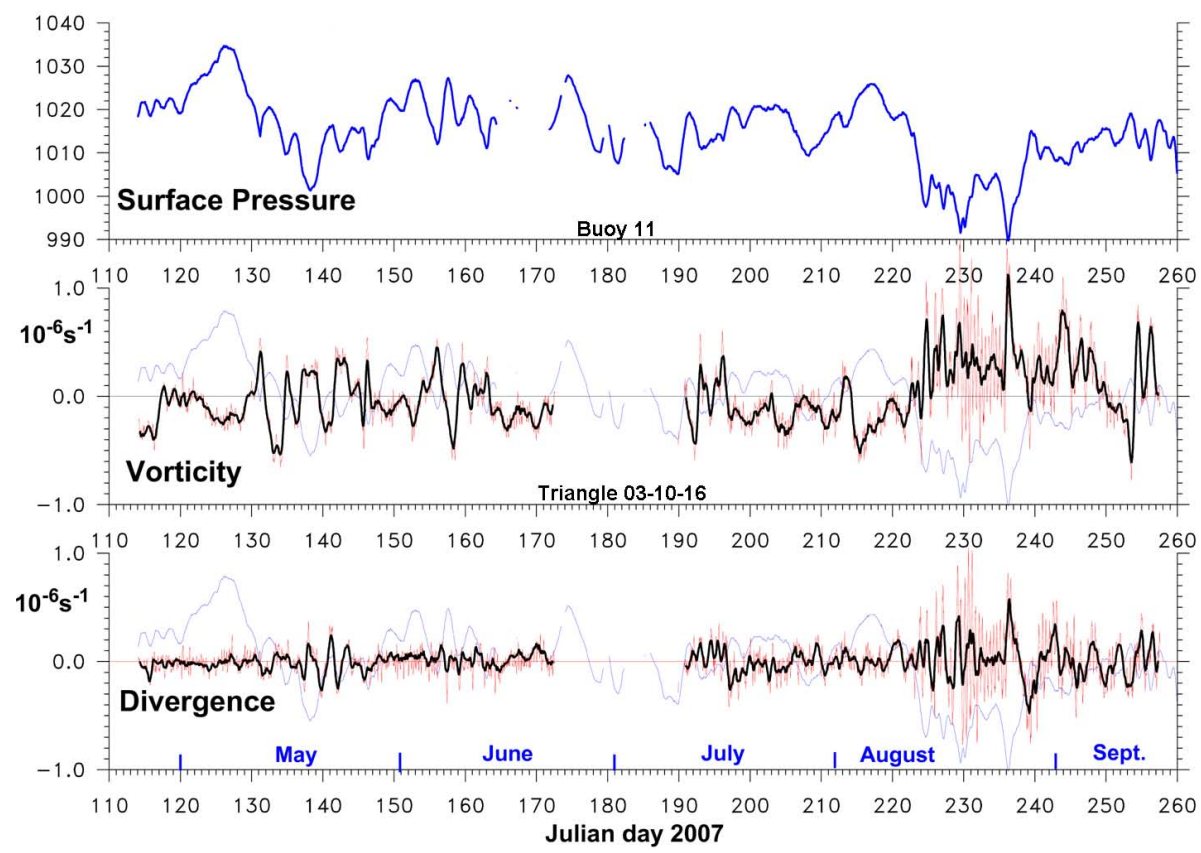

Fig. 9. Time series of ice-drift vorticity and divergence in the D07 buoy triangle $03-10-16$ with $2 \mathrm{~h}$ resolution (red) and as $12 \mathrm{~h}$ running mean (black) together with the sea-level pressure at buoy 11 in the middle of the triangle. To ease visual correlation the pressure is repeated as thin curve in the vorticity and divergence panels.

oscillations are not uncommon in the Arctic (Gimbert et al., 2012). Based on IABP data, Gimbert et al. (2012) analysed the spatial and seasonal variation of inertial oscillations and found a significant relation between the amplitude of the oscillations and the main ice properties, concentration and thickness (the amplitude is larger when the internal ice force is smaller). The maximum ice speed during the storm passage amounted to $53 \mathrm{~cm} \mathrm{~s}^{-1}$ at buoy 3 . This is a large value for the TPD in the North Pole region (the median value there is $7.5 \mathrm{~cm} \mathrm{~s}^{-1}$, Table 2) and is otherwise observed only at the ice edge or in the Fram Strait.

The area change corresponding to the divergence caused by the storm for the $24 \mathrm{~h}$ period from 12:00 UTC on $12 \mathrm{Au}-$ gust to 12:00 UTC on 13 August is between 0.1 and $3.6 \%$ depending on the sub-area. This is the integral storm effect; superimposed on this are oscillations of divergence and vorticity due to the oscillating ice motion. Table 5 shows for some triangles of the array maxima and minima of divergence and vorticity occurring during the oscillations on 13 August. Instantaneous divergence maxima during the oscillation amount to 4 times the integral $24 \mathrm{~h}$ divergence. The peak values for divergence are $1.67 \times 10^{-6} \mathrm{~s}^{-1}$ (corresponding to an area change of $0.6 \% \mathrm{~h}^{-1}$ ) in triangle 2-3-10 and those for vorticity are $2.67 \times 10^{-6} \mathrm{~s}^{-1}$ (corresponding to a rotation rate of $0.55^{\circ} \mathrm{h}^{-1}$ ). The minimum values of divergence and vorticity during the oscillation have negative signs but are absolutely smaller so that the above-mentioned integral effect remains. Opening and closing of the ice deck during the oscillation cycle does not return to the initial state of the ice field. It is an irreversible process. The relevance to account for the high-frequency component (inertial and tidal) of ice drift and deformation in ice models was demonstrated by Heil and Hibler (2002). They showed that this subsynoptic variability with short-period opening and closing of the ice cover can increase the generation of new ice by $20 \%$ in winter. In summer, this process contributes to an increased ice melt.

Thus, the impact of a cyclone has two aspects, an instantaneous one and a longer term one. (1) The synoptic wind field of a cyclone causes a more or less instantaneous divergent ice drift. (2) Even when the cyclone is gone, the induced inertial motions continue to work further on the ice field.

\section{Summary and conclusions}

Within the DAMOCLES research project, 18 ice buoys were deployed in the region of the TPD. Sixteen of them formed a square of $400 \mathrm{~km}$ side length. The measurements covered the period 2007-2009. The data were used to analyse the properties of the TPD and the impact of synoptic weather systems on the ice drift.

Compared to other studies (e.g. Gascard et al., 2008; Hakkinen et al., 2008; Rampal et al., 2009; Kwok et al., 2013), our Lagrange-type measurements also show that the TPD from the Siberian side to Fram Strait was almost twice as fast as 100 years ago during the drift of Norwegian vessel Fram. Within the TPD we find an increase of the drift speed 

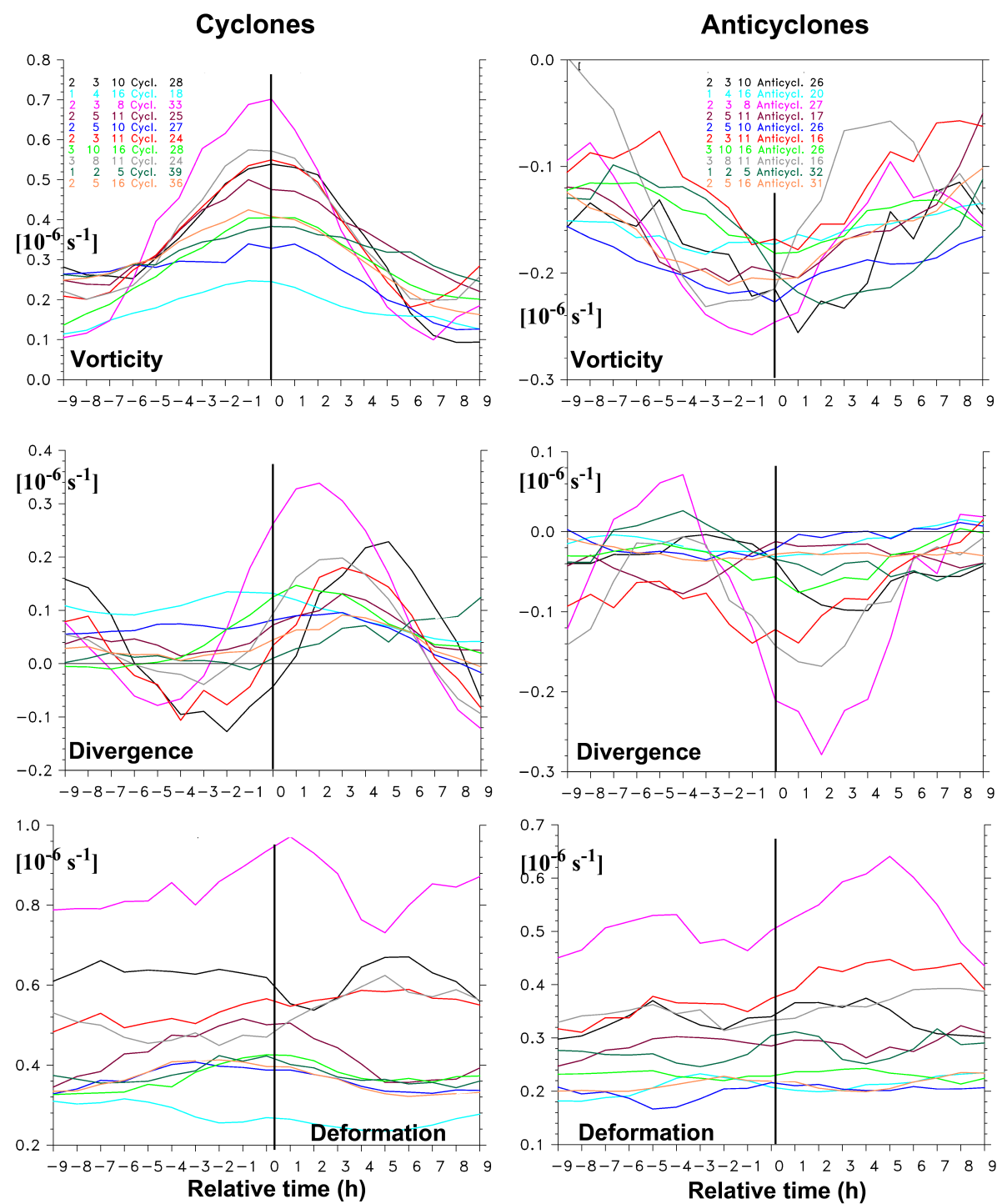

Fig. 10. Composite time development of ice-drift vorticity, divergence and magnitude of deformation for 10 different triangles within the D07 buoy array during cyclone (left) and anticyclone (right) passages. The time is relative to the vorticity maximum (minimum). The buoys and the number of cases used for each triangle composite are listed in the upper panels. Note the different ordinate scales for cyclones and anticyclones.

Table 4. Mean maximum-minimum difference of ice-drift oscillations in $\mathrm{cm} \mathrm{s}^{-1}$ in the D07 buoy array during the one-week period 13 and 19 August after the cyclone passage on 13 August.

\begin{tabular}{lrrrrrrrrrrrrrrrr}
\hline Buoy no. & 1 & 2 & 3 & 4 & 5 & 6 & 7 & 8 & 9 & 10 & 11 & 12 & 13 & 14 & 15 & 16 \\
\hline $\mathrm{cm} \mathrm{s}^{-1}$ & 7.9 & 16.2 & 16.2 & - & 6.3 & - & - & 15.0 & - & 5.1 & 9.8 & - & - & - & - & 7.7 \\
\hline
\end{tabular}

by a factor of almost 3 from the North Pole region towards Fram Strait. The high temporal resolution $(1-3 \mathrm{~h})$ of the buoy position fixes shows that the TPD is subjected to many detours manifested as curves and circles caused by passing weather systems. If the positions were taken at only 1-3 day intervals as it is typically done for satellite-based drift estimates, will underestimate the drift speed by $10-20 \%$.

The overall geostrophic wind factor $U_{\mathrm{i}} / U_{\mathrm{g}}$ in the TPD amounts to 0.012 , however, with regional and seasonal differences. The smallest values occur north of Greenland, the largest ones in the Fram Strait. Wind factor values are larger 


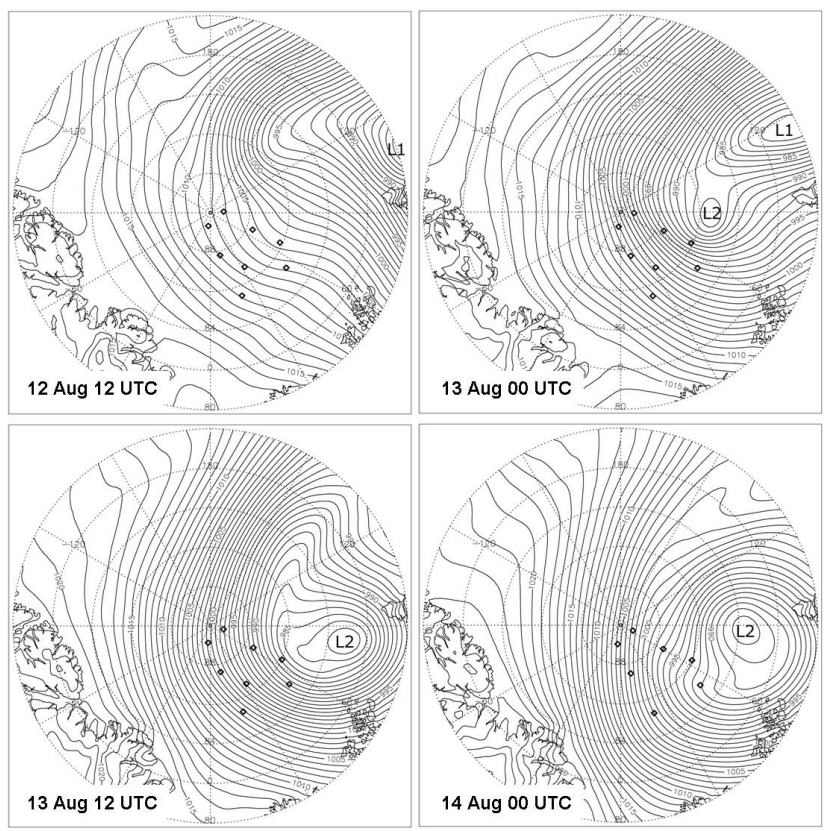

Fig. 11. Sea-level pressure fields from ECMWF operational analysis on 12 August, 12:00 UTC, 13 August, 00:00 UTC, 13 August, 12:00 UTC, and 14 August, 00:00 UTC together with simultaneous buoy positions. L1 and L2 mark low-pressure centres.

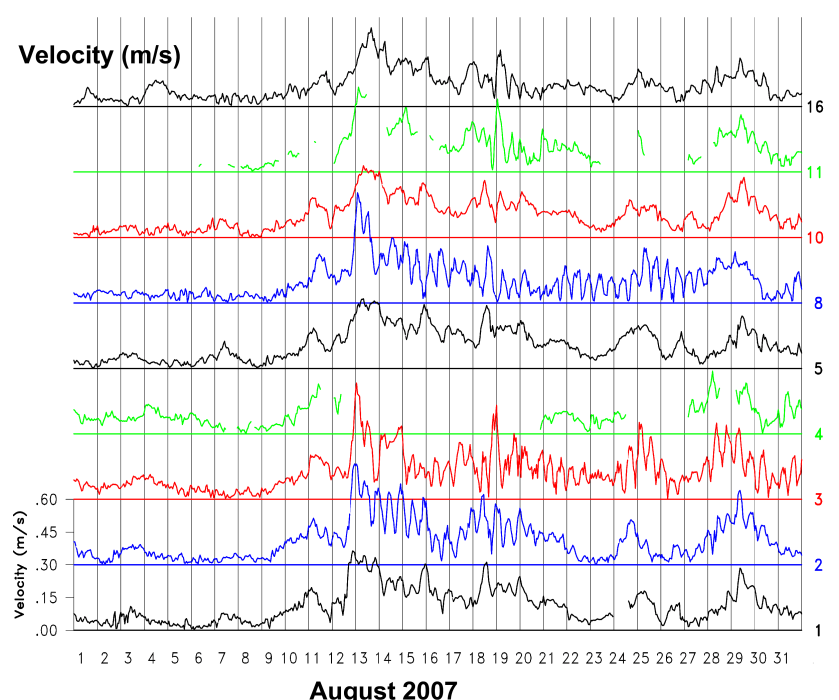

Fig. 12. Time series of hourly ice-drift magnitude in the D07 buoy array during August 2007. A different ice-drift regime begins with the storm on 13 August.

in summer than in winter as was also found by other authors (e.g. Thorndike and Colony, 1982; Kimura and Wakatsuchi, 2000). A distinct deviation from the above-mentioned wind factor to higher values occurs for $U_{\mathrm{g}}<5 \mathrm{~m} \mathrm{~s}^{-1}$ as was also found by, for example, Thorndike and Colony (1982). In contrast to these studies, we find no change of the an-

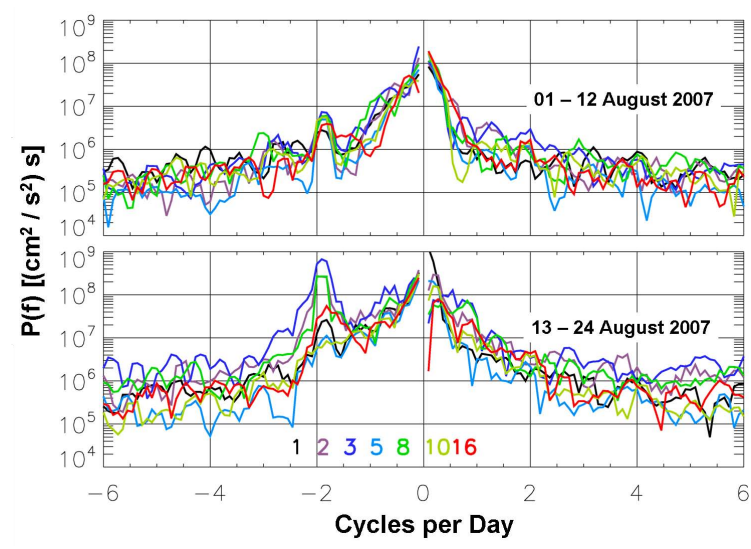

Fig. 13. Power spectra of ice-drift vector time series measured at 7 ice buoys (no. 1, 2, 3, 5, 8, 10, and 16) before (1-12 August 2007) and after (13-24 August 2007) the storm on 13 August 2007.

Table 5. Maxima and minima of ice-drift divergence and vorticity oscillations on 13 August 2007 for eight triangles of the D07 buoy array.

\begin{tabular}{|c|c|c|c|c|}
\hline \multirow[t]{2}{*}{ Triangle } & \multicolumn{2}{|c|}{$\begin{array}{l}\text { Divergence } \\
\text { in } 10^{-6} s^{-1}\end{array}$} & \multicolumn{2}{|c|}{$\begin{array}{c}\text { Vorticity } \\
\text { in } 10^{-6} \mathrm{~s}^{-1}\end{array}$} \\
\hline & Max & Min & Max & Min \\
\hline 02-03- & 167 & -1 . & 10 & -1.47 \\
\hline 02-03-08 & 1.47 & -2.00 & 2.67 & -1.33 \\
\hline $02-05-10$ & 0.67 & -0.47 & 0.93 & -0.40 \\
\hline $02-03-11$ & 1.07 & -1.33 & 2.00 & -0.73 \\
\hline $03-10-16$ & 0.47 & -0.27 & 1.00 & -0.53 \\
\hline $03-08-11$ & 1.33 & -0.80 & 2.00 & -0.73 \\
\hline $01-02-05$ & 0.53 & -0.53 & 1.07 & -0.80 \\
\hline $02-05-16$ & 0.80 & -0.67 & 0.93 & -0.93 \\
\hline
\end{tabular}

gle difference $\alpha_{\mathrm{i}}-\alpha_{\mathrm{g}}$ with $U_{\mathrm{g}}$. Spatial differences of $U_{\mathrm{i}} / U_{\mathrm{g}}$ were present within the D07 buoy array at the beginning of the field experiment and still existed five months later. This demonstrates that characteristics of the ice cover have a long lifetime.

The influence of synoptic weather systems on the sea ice was studied applying a composite method. Cyclonic weather systems cause cyclonic vorticity and divergence whereas anticyclonic systems cause anticyclonic vorticity and convergence of the ice drift. The amplitude of the variations is about twice as large for cyclones as for anticyclones. The temporal evolution of divergence is asymmetric with respect to the passage time. Maximum values of divergence (convergence) occur after the cyclone (anticyclone) passage. Typical divergence values are $0.1-0.5 \%$ per $6 \mathrm{~h}$ indicating the generation of open water areas. Causes for the asymmetry are not exactly understood, but probably are related to the fact that the approaching (leaving) system works on yet unmodified (already modified) ice field. 
A strong summer storm caused a step-like rise of drift speed which remained over several weeks. In addition, the ice cover was modified in a way allowing large amplitudes of inertial ice motion, also remaining over several months. The storm-related divergence caused an increase of open water areas of up to $3.6 \%$ in some parts of the array. Thus, cyclones have a primary immediate effect (divergence) and a secondary subsequent effect (inertial motion) on the ice field.

Following the studies of an increased cyclone frequency in the Arctic (e.g. Affeld, 2003; Zhang et al., 2004; Serreze and Barrett, 2008; Haller, 2011) and combining them with our results, this must have been accompanied by an increased icedrift divergence and by corresponding, previously mentioned different consequences in summer (more ice melt) and winter (more ice formation). Whether the observed long-term acceleration of the speed of the TPD is more a direct consequence of the increased cyclone activity and thus a higher surface stress or whether it is more an indirect consequence of the cyclone-related ice divergence and thus a smaller internal ice stress cannot be answered here, but is an open scientific issue. For the period 2001-2009, Kwok et al. (2013) find large spatially averaged drift speed trends of about $20 \%$ per decade but much smaller wind speed trends. This underlines the importance of the indirect effect of the wind forcing which is to reduce the internal ice stress.

Our measurements also show that already a single storm, when exceeding certain thresholds, can have long-term consequences for the ice cover (at least in summer). Perovich et al. (2012) argue that a severe storm in August 2012 (the year with the latest record ice extent minimum in September) accelerated the ice loss in the Pacific Arctic. Exceeding of thresholds means both thresholds of the atmospheric forcing and thresholds of the properties of the ice deck. Because of the non-linearity implied by these thresholds the simulation and prognosis of the Arctic ice cover remains a challenging sensitive task.

Acknowledgements. This paper has received support by the integrated research project DAMOCLES within the EU 6th framework programme.

Edited by: K. Dethloff

\section{References}

Affeld, B.: Zyklonen in der Arktis und ihre Bedeutung für den Eistransport durch die Framstraße, PhD thesis, 125 pp., University Hamburg, Germany, 2003.

Brümmer, B., Schröder, D., Müller, G., Spreen, G., JahnkeBornemann, A., and Launiainen, J.: Impact of a Fram Strait cyclone on ice edge, drift, divergence, and concentration: possibilities and limits of an observational analysis, J. Geophys. Res., 113, C12003, doi:10.1029/2007JC004149, 2008.

Brümmer, B., Müller, G., Haller, M., Kriegsmann, A., Offermann, M., and Wetzel, C.: DAMOCLES 2007-2008 -
Hamburg Arctic Ocean buoy drift experiment: meteorological measurements of 16 autonomous drifting ice buoys, doi:10.1594/wdcc/uni_HH_MI_DAMOCLES2007, 2011a.

Brümmer, B., Müller, G., Haller, M., Kriegsmann, A., Offermann, M., and Wetzel, C.: DAMOCLES 2008-2011 Hamburg Arctic Ocean buoy drift experiment: meteorological measurements of 9 autonomous drifting ice buoys, doi:10.1594/wcdc/uni_HH_MI_DAMOCLES2008, 2011b.

Gascard, J.-C., Festy, J., Le Goff, H., Weber, M., Brümmer, B., Offermann, M., Doble, M., Wadhams, P., Forsberg, R., Hanson, S., Skourup, H., Gerland, S., Nicolaus, M., Metaxian, J.-P., Grangeon, J., Haapala, J., Rinne, E., Haas, C., Heygster, G., Jacobson, E., Palo, T., Wilkinson, J., Kaleschke, L., Claffey, K., Elder, B., and Bottenheim, J.: Exploring Arctic transpolar drift during dramatic sea ice retreat, EOS Transactions, 89, 21-28, 2008.

Gimbert, F., Marsan, D., Weiss, J., Jourdain, N. C., and Barnier, B.: Sea ice inertial oscillations in the Arctic Basin, The Cryosphere, 6, 1187-1201, doi:10.5194/tc-6-1187-2012, 2012.

Haapala, J., Lönnroth, N., and Stössel, A.: A numerical study of open water formation in sea ice. J. Geophys. Res., 110, C09011, doi:10.1029/2003JC002200, 2005.

Hakkinen, S., Proshutinsky, A., and Ashik, I.: Sea ice drift in the Arctic since the 1950s, Geophys. Res. Lett., 35, L19704, doi:10.1029/2008GL034791, 2008.

Haller, M.: Arktische Zyklonen und Meereeisdrift während der DAMOCLES-Bojenexperimente 2007-2010, PhD thesis, 201 pp., University Hamburg, Germany, 2011.

Heil, P. and Hibler III, W. D.: Modeling the high-frequency component of Arctic sea ice drift and deformation, J. Phys. Oceanogr., 32, 3039-3057, 2002.

Hutchings, J., Roberts, A., Geiger, C., and Richter-Menge, J.: Spatial and temporal characterisation of sea ice deformation, Ann. Glaciol., 52, 360-368, 2011.

Hutchings, J., Heil, P., Steer, A., and Hibler III, W. D.: Subsynoptic scale spatial variability of sea ice deformation in the western Weddell Sea during early summer, J. Geophys. Res., 117, C01002, doi:10.1029/2011JC006961, 2012.

Kawaguchi, Y. and Mitsudera, H.: A numerical study of ice-drift divergence by cyclonic wind with a Lagrangian ice model, Tellus A, 60, 789-802, 2008.

Kimura, N. and Wakatsuchi, M.: Relationship between sea-ice motion and geostrophic wind in the Northern Hemisphere, Geophys. Res. Lett., 27, 3735-3738, 2000.

Kriegsmann, A. and Brümmer, B.: Cyclone impact on sea ice in the central Arctic Ocean: a statistical study, The Cryosphere Discuss., 7, 1141-1176, doi:10.5194/tcd-7-1141-2013, 2013.

Kwok, R., Cunningham, G. F., and Pang, S. S.: Fram Strait sea ice outflow, J. Geophys. Res. 109, C01009, doi:10.1029/2003JC001785, 2004.

Kwok, R., Spreen, G., and Pang, S.: Arctic sea ice circulation and drift speed: decadal trends and ocean currents, J. Geophys. Res.Oceans, 118, 2408-2425, doi:10.1002/jgrc.20191, 2013.

Lammert, A., Brümmer, B., and Kaleschke, L.: Observation of cyclone-induced inertial sea-ice oscillation in Fram Strait, Geophys. Res. Lett., 36, L10503, doi:10.1029/2009GL037197, 2009.

Leppäranta, M.: The drift of sea ice. Textbook, 266 pp., SpringerVerlag, Berlin Heidelberg New York, 2005. 
Perovich, D., Meier, W., Tschudi, M., Gerland, S., and RichterMenge, J.: Sea ice (in Arctic Report Card 2012), 37-42, available at: http://www.arctic.noaa.gov/report12/sea_ice.html (last access: 12 February 2014), 2012.

Rampal, P., Weiss, J., Marsan, D., Lindsay, R., and Stern, H.: Scaling properties of sea ice deformation from buoy dispersion analysis, J. Geophys. Res., 113, C03002, doi:10.1029/2007JC004143, 2008.

Rampal, P., Weiss, J., and Marsan, D.: Positive trend in the mean speed and deformation rate of Arctic sea ice 1979-2007, J. Geophys. Res., 114, C05013, doi:10.1029/2008JC005066, 2009.

Rösel, A. and Kaleschke, L.: Exceptional melt pond occurrence in the years 2007 and 2011 on the Arctic sea ice revealed from MODIS satellite data, J. Geophys. Res., 117, C05018, doi:10.1029/2011JC007869, 2012.

Screen, J. A., Simmonds, I., and Keay, K.: Dramatic interannual changes of perennual Arctic sea ice linked to abnormal summer storm activity, J. Geophys. Res.-Atmos., 116, D15105, doi:10.1029/2011JD015847, 2011.
Serreze, M. C. and Barnett, A. P.: The summer cyclone maximum over the central Arctic Ocean, J. Climate, 21, 1048-1065, 2008.

Smedsrud, L. H., Sirevaag, A., Kloster, K., Sorteberg, A., and Sandven, S.: Recent wind driven high sea ice area export in the Fram Strait contributes to Arctic sea ice decline, The Cryosphere, 5, 821-829, doi:10.5194/tc-5-821-2011, 2011.

Thorndike, A. S. and Colony, R.: Sea ice motion in response to geostrophic winds, J. Geophys. Res., 87, 5845-5852, 1982.

Vihma, T., Tisler, P., and Uotila, P.: Atmospheric forcing on the drift of Arctic sea ice in 1989-2009, Geophys. Res. Lett., 39, L02501, doi:1029/2011GL050118, 2012.

Vinje, T.: Fram Strait ice fluxes and atmospheric circulation 19502000, J. Climate, 14, 3508-3517, 2001.

Zhang, X., Walsh, J., Zhang, J., Bhatt, U., and Ikeda, M.: Climatology and interannual variability of Arctic cyclone activity, J. Climate, 17, 2300-2317, 2004. 